\title{
El Congreso centralista y la guerra de Texas
}

$\mathrm{L}$

a situación política de México a mediados de los años treinta del siglo pasado era desoladora. Después de una sangrienta guerra civil, que consumió grandes recursos económicos y humanos, y del fracaso de la primera reforma liberal, que puso en conmoción el orden social, el país estaba a punto de la anarquía total.

Durante todo el año de 1834, el general Santa Anna trató de mantenerse en un justo medio y así, por un lado, suspendió la mayor parte de la legislación anticlerical de la administración de Gómez Farías y, por otro, sostuvo contra viento y marea el sistema federal, a pesar de que las presiones para cambiarlo aumentaban día a día. Convocó a elecciones porque en ese periodo tenía el convencimiento de que un cambio sería muy peligroso para la nación. ${ }^{1}$ Santa Anna contaba también con una circunstancia a su favor: las personas estaban cansadas de los partidos y del continuo vaivén de la política; ${ }^{2}$ de esta manera la so-

1 Gobierno General, Primera Secretaría de Estado, "Circular a los gobernadores de los estados", México, 9 de julio de 1834, 1 y 15 de octubre de 1834, Archivo General de la Nación (AGN), Fondo Gobernación.

2 Es representativo del momento el siguiente comentario: "En dos bandos opuestos esta hoy dividida ostensiblemente la república y ambos se han disputado y disputan en acérrima guerra la preponderancia y el poder. Uno quiere los privilegios, las exacciones injustas y el derecho a dominarlo todo a título de hereditario; y otro, adulando al pueblo, y queriendo pervertirlo, aspira a una libertad sin límites, sin más dique que el capricho de los que la pretenden. Ambos en su apogeo los hemos visto, más o menos, separarse del sendero de la justicia, matar, desterrar y despojar propiedades; y por lo que 
lución parecía estar en la formación del nuevo Congreso.

Las elecciones se realizaron, en términos generales, en un clima de bastante tranquilidad, a pesar de las circunstancias por las que atravesaba el país. Esta visión positiva del acto electoral, sin embargo, no debe inducirnos a error; dos hechos incuestionables se dieron en estas elecciones: el dominio del partido del orden en las legislaturas de los estados, y la ausencia de los liberales o federalistas exaltados, de la escena política. ${ }^{3}$

toca a sus pretensiones, tan exageradas e incompatibles con el bien público son las de los unos como las de los otros; de manera que del triunfo de cualquiera de ellos no puede aspirarse, y no resultarán sino males y más males." El Censor de Veracruz, 30 de junio de 1834.

3 Uno de los problemas más dificiles de la época es el de la definición de los grupos o partidos políticos. Para Daniel Moreno un partido político es la "agrupación permanente y organizada de ciudadanos, que mediante la conquista legal del poder político, se propone realizar en la dirección del Estado, un determinado programa político social". Aunque en la época que estudiamos se hablaba de partidos políticos, a estos les faltaban las dos primeras características de la definición anterior. Más bien podemos decir que los partidos políticos de los años treinta del siglo pasado fueron grupos de personas que se reconocieron por pensar de la misma forma, por tener intereses comunes o por lazos de amistad, simpatía o parentesco. Por lo tanto, al no contar con una organización y compromisos claros, los hombres pasaban de un grupo a otro con facilidad y las agrupaciones políticas se hacían y deshacían con la misma facilidad. Ia división básica de los partidos de la época era de dos: el del progreso y el del orden, cada uno de ellos con su doble rama de exaltados y moderados. En estos años no se utilizaba la denominación de partido liberal y conservador, en cambio se hablaba de los liberales y hombres de bien o serviles. La definición de cada partido podría ser la siguiente: 1) Partido del progreso (o liberales): era federalista; estaba en
Las fuerzas políticas que estarian representadas en el Congreso, al instalarse en enero de 1835 , serían los seguidores del general Santa Anna, los moderados de ambos partidos y los exaltados dentro del partido del orden, que interpretaban el Plan de Cuernavaca y todo el movimiento producido por éste en el sentido de un cambio en la forma de gobierno. ${ }^{4}$

El Congreso durante 1835, después de un largo proceso, llegaría a la con

contra de los privilegios de la iglesia y el ejército; quería la libertad de imprenta; la supresión de las instituciones monásticas; la educación fuera del control de la Iglesia. La división entre moderados y exaltados se daba sobre todo por las cuestiones religiosas; los últimos querían reformas rápidas y de fondo, los moderados pensaban en cambios a largo plazo y que no afecta. ran el poder económico de la Iglesia. 2) Partido del orden: pretendía respetar los fueros de la Iglesia y del ejército, pero con control del gobierno; centralismo o federalismo matizado, no tan radical como el norteamericano; libertad de imprenta con restricciones; eliminación de las milicias cívicas; restricción en la participación política. La diferencia entre los moderados y los exaltados se daría por la forma de gobierno y las relaciones con la Iglesia. Los exaltados se definirian por el centralismo y el respeto de todos los privilegios de la Iglesia; los moderados podian ser federalistas y veían la necesidad de realizar reformas en algunos aspectos de la disciplina eclesiástica. 3) Partido de Santa Anna, es el tercero en discordia que rompe el equilibrio y debe considerarse más bien como la clientela política que se movía alrededor del caudillo; normalmente se colocaba en las posiciones moderadas de ambos partidos; defendía sobre todo los fueros del ejército, no se comprometía mucho con los asuntos eclesiásticos, veía en Santa Anna un agente providencial, único capaz de mantener el orden en el país y se incli. naba más bien por un federalismo moderado.

- El Plan de Cuernavaca, mayo de 1834, inició el movimiento que destituyó a Valentín 
clusión de que tenía plenos poderes otorgados por la nación para variar la forma de gobierno. En septiembre las dos cámaras reunidas en una sola se convertirían en Congreso constituyente. El 23 de octubre del mismo año el Congreso aprobaría las Bases para la nueva Constitución, dando fin al sistema federal.

A lo largo de la actuación del Congreso durante 1835 se puede constatar que los federalistas moderados fueron siempre una minoría de oposición, que si bien no podía modificar los acuerdos, sí los matizaba en un sentido de moderación. Los partidos de Santa Anna no estuvieron muy bien definidos durante este año; algunos de ellos empezaron votando con los federalistas, pero después se unieron a los centralistas; en la discusión de las $\mathrm{Ba}$ ses volvemos a encontrar a algunos de ellos en la oposición; de todas formas, en los asuntos a tratar siempre se encontraban en el justo medio.

Los moderados del partido del orden formaban un grupo importante y su trayectoria en el Congreso es muy significativa: en los primeros meses dejaron sentir su presencia, conformándose con las reformas a la Constitución de 1824 , pero, después del levantamiento de Zacatecas, ${ }^{5}$ deci-

Gómez Farías y se refería primordialmente a las reformas eclesiásticas.

5 El gobierno del estado de Zacatecas se levantó en armas frente al central, a raíz de un decreto del Congreso sobre arreglo de la milicia cívica. Este arreglo significaba la extinción de la milicia cívica, que era considerada como la principal defensa del sistema federal. Santa Anna venció a los milicianos de Zacatecas, en mayo de 1835 , mediante una campaña militar ridícula y sin importancia. didamente empezaron a votar por el centralismo; sin embargo, una vez realizada la unión de las cámaras, y sobre todo en la discusión de las $\mathrm{Ba}$ ses, los encontramos en la oposición o en la búsqueda de la posición intermedia; finalmente, el grupo centralista, sin duda el más numeroso, siguió también una táctica de moderación y compromiso, ajustándose siempre a las circunstancias. ${ }^{6}$

Es decir, el tránsito al centralismo dentro del Congreso se logró por una alianza de los centralistas, los modera. dos del partido del orden y los partidarios del general Santa Anna, después de la derrota de Zacatecas; una vez logrado el propósito del Congreso de convertirse en constituyente, volvió a darse una escisión entre los dos últimos y el primero; y gracias a este aumento de la oposición, las Bases para el gobierno centralista fueron una solución intermedia.

Al mismo tiempo que se daba el cambio al sistema centralista, el Congreso abordaba diversos asuntos refe-

6 Entre los miembros más destacados de cada partido, podemos encontrar: a) centralistas: Francisco Manuel Sánchez de Tagle, Basilio Arrillaga, José Ignacio Anzorena, José María Cuevas, Carlos María de Bustamante, Mariano Michelena, Miguel Valentín, Rafael Berruecos; $\boldsymbol{b}$ ) moderados del partido del orden: Jose Luciano Becerra, Francisco García Conde, Ignacio Ormaechea, José Antonio Arce, José Ramón Malo y Pedro Espinosa; c) santanistas: Demetrio del Castillo, Néstor Escudero, Manuel Larraínzar, José Miguel Pacheco, Ignacio Gutiérrez, Ignacio Loperena, Tomás O'Horan y Antonio Pacheco Leal; d) federalistas moderados: Guadalupe Victoria, Luis Movellán, Joaquín Parrés, Pedro Ramírez, Víctor Blanco, José Bernardo Couto, Luis Gordoa, Juan Martín de la Garza y Pedro Ahumada. Sordo, "Congreso", 1989, I, anexo 2. 


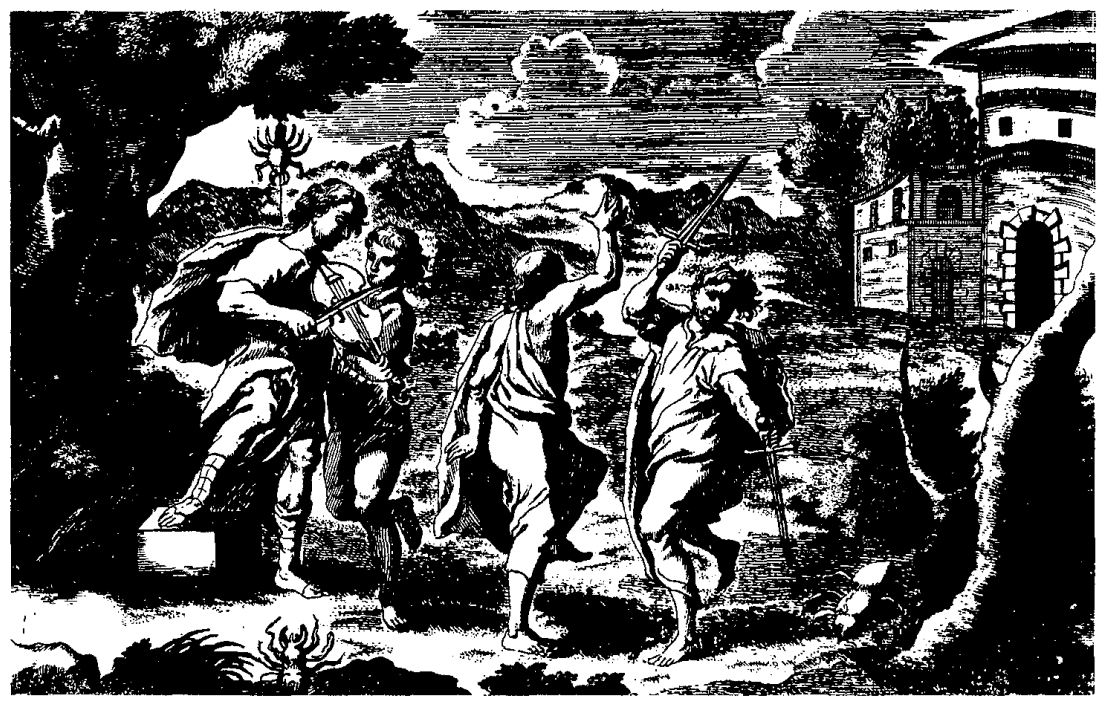

ridos al estado de Coahuila y Texas que de alguna forma afectarían la posición de los colonos texanos hacia México. Coahuila y Texas serían un tema frecuente en los debates del Congreso. De esta forma, el Congreso general declaró contrarios a la Constitución el decreto número 22 de la legislatura de Coahuila y Texas del 11 de marzo de 1826 , el del 21 de febrero de 1834 sobre los bienes pertenecientes al concurso de Aguayo y el del 14 de marzo de 1835 sobre la venta de terrenos baldíos, y facultó al gobierno para restablecer el orden público en el estado, de acuerdo al decreto del día 2 de diciembre del año anterior. ${ }^{7}$

7 Las tres primeras leyes declararon inconstitucionales a tres correspondientes decretos de la legislatura de Coahuila y Texas. Por el de 1826
Esta última disposición tuvo como resultado la huida del gobernador Agustín Viezca y su aprehensión, que incidieron en una actividad ya plenamente de rebeldía de parte de los colonos angloamericanos hacia las autoridades mexicanas. Los colonos de la jurisdicción de Austin se pronunciaron

se habían concedido facultades extraordinarias, ilimitadas al gobernador, que atentaban contra Ios derechos de los ciudadanos. El del 21 de febrero de 1834 había confiscado las propiedades del marquesado de San Miguel de Aguayo; el problema era que previamente habían sido traspasadas a una compañía inglesa. Por el del 14 de marzo de 1835, el Congreso estatal disponía de los terrenos baldíos para enajenarlos sin restricciones. Finalmente, el último decreto facultaba al presidente de la república para restablecer el orden que se había alterado en Coahuila y Texas desde el ano anterior. AGN, Fondo Gobernacion: 1835, s/c. 
en San Felipe, el 22 de junio, decididos a sostener la Constitución federal y la del estado de Coahuila y Texas. En un Manifiesto mostraban con claridad, a través de ocho puntos, una oposición decidida al cambio en la forma de gobierno, a las usurpaciones y violaciones que, consideraban, había ejercido el gobierno central, anulando los derechos de los estados. ${ }^{8}$ A partir de este momento Texas se convirtió en uno de los problemas centrales de aquellos años.

Ia historiografia oficial considera al cambio de ia forma de gobierno como la causa principal de la rebeldía de los colonos; esta tesis nadie la sustenta seriamente. A mí me interesa indagar de qué forma afectó la cuestión de Texas a este Congreso general que realizó el cambio de la forma de gobierno, y a las posibilidades de alcanzar estabilidad en el proyecto político del cen. tralismo. Pienso que la cuestión de Texas fue decisiva en las posibilidades del proyecto centralista constitucional y, para poder sustentar esta afirmación, me gustaría analizar tres as. pectos: el de legitimidad, el de re. cursos económicos y el del comportamiento de las fuerzas políticas.

Cuando la rebelión estaba en mar. cha, el país se encontraba en una coyuntura peligrosa. El Congreso que realizaba el cambio era muy cons. ciente de esta situación; por eso, la comisión que presentó los proyectos de ley para reorganización de la

- "Pronunciamiento del estado libre de Coahuila y Texas", San Felipe de Austin, 22 de junio de 1835, R. M. Williamson, Biblioteca Nacional (BN), Colección Lafragua (impreso suelto). república, en las sesiones de 24 y 25 de septiembre de 1835 , afirmaba lo siguiente:

El estado de la república es verdaderamente peligroso, y está al alcance de todos lo crítico de nuestra situaciôn. Partidos que tratan de suplantarse y reparar sus quiebras; díscolos que esperan medrar en el desorden; ambiciosos y famélicos que temen perder los puestos y empleos en que sin mérito y sin trabajo han fincado su subsistencia; gobernantes tímidos, porque consideran su autoridad muy precaria y próxíma a cambiar; gobernados insolentados, porque creen rotas o desatadas las ligaduras de las leyes; leyes sospechadas de insubsistencia, y por lo mismo lánguidas y sin vigor; estados sin gobernadores ni legislaturas, por haber faltado en unos totalmente, y habérseles minorado en otros el prestigio y la fuerza moral; un gobierno general entrabado para hacer el bien por leyes que no deben existir, e inhábil para obrar por falta de las que deben darse: tal es, en bosquejo im. perfecto, nuestra sociedad; tal, y mucho peor la crisis en que se halla. De esta situación a la anarquía desenfrenada no hay ni dos dedos de distancia. ${ }^{9}$

Esta etapa de "incertidumbre precaria o anarquía moderada", como la llamaría Francisco Manuel Sánchez de Tagle, duraría más de un año, hasta la promulgación de la Constitución de las Siete Leyes, en diciembre de 1836. Todo ese tiempo corresponde a los preparativos de la expedición hacia Texas, a su desarrollo exitoso en las pri-

9 Proyectos, 1835. 
meras acciones, a su fracaso en San Jacinto, a su consecuencia en los tratados de Velasco, a la prisión del general Santa Anna, a su liberación, a su viaje a los Estados Unidos y a su regreso a nuestro país.

La elaboración de las Siete Leyes quedó de esta forma ligada inseparablemente al trauma de una derrota inexplicable cuando todos los primeros sucesos hacían prever un éxito completo. $\mathrm{Y}$, sin duda, no hay una correlación entre una y otra, pero, ¿qué prestigio podría tener una ley que antes de aplicarse tenía en su haber un fracaso tan grande? iSobre qué argumentos podría apoyarse el partido del orden para ponderar los beneficios del sistema central, después de la derrota de San Jacinto?

El Congreso, por otra parte, siempre se ocupó del problema de Texas y trató de poner en movimiento todos los elementos a su alcance para reducir al orden a los colonos sublevados. A finales de 1835 se creó una comisión especial para dedicarse exclusivamente a los asuntos texanos, integrada por los representantes Francisco Manuel Sánchez de Tagle, Mariano Michelena, Rafael Berruecos, Miguel Valentín y Juan Martín Garza Flores, entrando en ocasiones como suplente Juan Manuel Elizalde. ${ }^{10}$ También dio disposiciones para allegarse recursos, que analizaremos más adelante, $y$ trató de utilizar el conflicto para lograr un consenso en el país y llegar a la siem. pre aspirada unidad nacional.

$10 C f$ : , Archivo del Instituto de Investigaciones Legislativas (AIIL), Actas de las sesiones secretas.
El señor secretario de la Guerra se presentó a dar cuenta al Congreso, el día 19 de mayo de 1836 , de un oficio del general Filisola, en el que se comunicaba el resultado de la acción de San Jacinto. ${ }^{11}$ El día siguiente, en sesión secreta, la comisión especial sobre Texas presentó un dictamen que fue aprobado por mayoría. En él se excitaba al patriotismo de los mexicanos, se autorizaba al gobierno para continuar "vigorosamente la guerra sobre Texas" y se declaraba nulo, de ningún valor y efecto, cualquier tratado convenido por el presidente en prisión con los colonos de Texas. ${ }^{12}$

El gobierno, en la sesión del día 13 de junio leyó al Congreso comunicaciones de los generales Urrea y Ramírez Sesma con el general Filisola; se hizo mención de un tratado celebrado por el presidente; el gobierno pidió al Congreso manifestase a la nación cuál era el deber de todo mexicano en esas circunstancias y que se le otorgasen los recursos necesarios; el Congreso aprobó una iniciativa para dar un manifiesto a la nación. ${ }^{13}$

La comisión de Texas presentó el Manifiesto el día 14 de julio; el señor Tagle señaló que la comisión era de la opinión de que no se diese, pero por acuerdo del Congreso se presentaba a la discusión; después de observaciones y modificaciones sobre su contenido, el Manifiesto apareció pu.

11 Congreso, "Sesión del día 19 de mayo de 1836", Mateos, Historia, 1877, vol. XI, pp. 372 377.

1220 de mayo de 1836, "Ley", Dublán y Lozano, Colección, 1876-1904, vol. III, p. 162.

13 Congreso, "Sesión del día 13 de junio de 1836", Mateos, Historia, 1877, vol. xI, p. 415. 


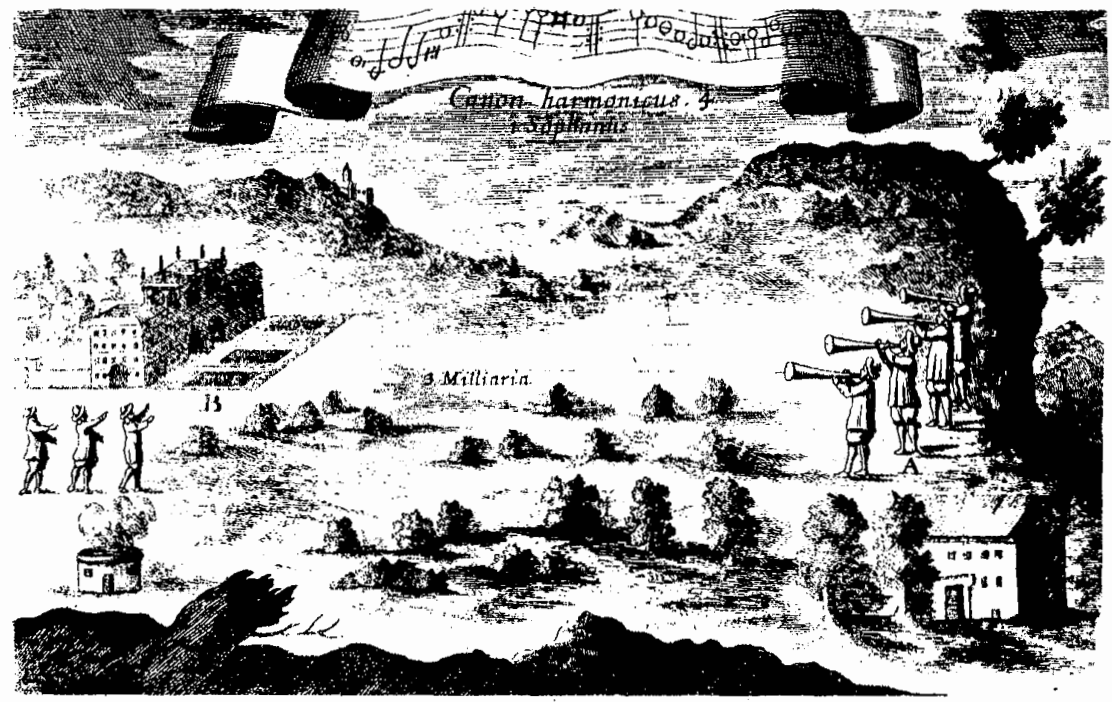

blicado en el Diario Oficial el día 9 de agosto. ${ }^{14}$

El documento es excesivamente retórico, pero en él se nota una intención muy clara: despertar el patriotismo en los mexicanos, acabar con las discordias internas y actuar con unidad alrededor del gobierno y el Congreso. Por eso se declara:

La guerra que proseguimos es verdaderamente nacional, como que no se trata de intereses privados, sino del honor mexicano, de la integridad del territorio, de la conservación de la paz e independencia $[\ldots]$ Sea pues unión y de-

14 "Manifiesto del Congreso general en el presente año", Diario del Gobierno de la República Mexicana, 9 de agosto de 1836 . cisión; plena confianza en el ejecutivo $[\ldots]^{15}$

Sin embargo, el Congreso no logró despertar un gran patriotismo en el pueblo ni un apoyo sustancial al proyecto centralista. Si es cierto que en los periódicos de la época vemos suscripciones para la guerra de Texas, casi siempre éstas eran ridículas en su monto. Tampoco se ofrecieron al gobierno masas de hombres dispuestos a sacrificarse en los desiertos de Texas por el honor nacional. La dura realidad se fue imponiendo, y al contra. rio de lo que se suponía, las contribuciones necesarias para la guerra de Texas fueron un peso más que el pueblo

15 Ibid. 
soportó contra su voluntad y que lo alejó necesariamente de los hombres que ejercían el poder.

La guerra de Texas contribuyó también a debilitar al estado centralista en formación por las urgentes necesidades de recursos de un gobierno en bancarrota. Dilema insoluble el de compaginar la guerra de Texas con el saneamiento de las finanzas públicas. Para allegarse recursos, el Congreso comenzó por plantear un subsidio extraordinario de guerra, en noviembre de 1835 . El proyecto se discutió en noviembre y apareció como ley el 21 de dicho mes. Esta contribución afectaba a los propietarios de fincas urbanas, quienes deberian contribuir por una vez en clase de subsidio extraordinario de guerra con el $1 \%$ del valor en que habían comprado sus fincas. ${ }^{16}$

En junio de 1836 , en sesiones secretas, el señor Garza Flores pidió que el Congreso se declarase en sesión permanente hasta proporcionar recursos al gobierno. La propuesta se discutió largamente y el 16 apareció sancionada por el gobierno en forma de ley; por ella se autorizaba al gobierno para exigir un préstamo forzoso en toda la república, hasta de 2000000 de pesos, exigiendo como máximo la cantidad de 1000 pesos. De acuerdo con la ley, la exacción șe dividió en cuatro clases: $1000,500,200,100$ y 50 pesos, de manera que ésta ya no sólo recaía en la clase propietaria. ${ }^{17}$

E1 30 de junio se estableció una con-

1621 de noviembre de 1835, "Ley", Dublán y Lozano, Coleccion, 1876-1904, vol. III, p. 102.

17 Congreso, "Sesión secreta extraordinaria del 15 de junio de $1836^{\prime \prime}$, all, Actas de las sesiones secretas. tribución sobre el valor de las fincas urbanas de dos al millar; es decir, que lo que en un principio había sido ex. cepcional, se volvía permanente. ${ }^{18} \mathrm{El}$ 5 de julio de 1836 se estableció una contribución de tres al millar, sobre el valor de las fincas rústicas en la república. ${ }^{19}$ Dos días después, el Congreso estableció un derecho de patente por el cual, todas las casas de comercio, para poder seguir funcionando o establecerse de nuevo, deberían adquirir una patente del gobierno, mediante el pago de una contribución. ${ }^{20}$

Las contribuciones iban aumentando en el periodo de la "anarquía moderada" que analizamos; éstas habian afectado a propietarios de fincas urbanas, a hacendados, a trabajadores cuyo único capital era su trabajo, a comerciantes, en grande y en pequeño, y a los artesanos, es decir a las principales clases productivas del país. Es claro que las contribuciones no iban destinadas exclusivamente a la guerra de Texas y que la bancarrota venía descle los años de la Independencia. Sin embargo, el conflicto con los colonos en esos años llevó a los gobernantes a continuar y profundizar el método de las exacciones extraordinarias y los contratos ruinosos, con el objeto de salir de los apuros del momento, en lugar de poner en práctica un sistema de hacienda coherente y de mediano plazo que diera estabilidad al Estado.

1830 de junio de 1836, "Ley", Dublán y Lozano, Coleccion, 1876-1904, vol. ill, p. 169.

195 de julio de 1836, "Ley", Dublán y Lozano, Coleccion, 1876-1904, vol. III, p. 176.

207 de julio de 1836 , "Ley", Dublán y Lozano, Coleccion, 1876-1904, vol. II, p. 178. 
Las exacciones rindieron muy pobres frutos, la guerra de Texas no pudo reemprenderse, el ejército del norte se convirtió en un "espectro" y el sistema central, antes de ponerse en funcionamiento en abril de 1837, era cuestionado por amplios sectores de la sociedad.

El aspecto en que afectó mâs el conflicto con los texanos fue el de la composición de fuerzas políticas, dentro y fuera del Congreso, que habia hecho posible el cambio en la forma de gobierno. Las cuatro fuerzas a que hicimos referencia habían seguido un proceso de compromisos que, después de discutir las Bases y en el momento de comenzar a debatir las leyes constitucionales, estaban a punto de romperse.

La posición que había adoptado el general Santa Anna y su grupo fue un factor importante en el cambio al centralismo. Santa Anna se había opuesto al cambio eń 1834 y a principios de $1835 \mathrm{y}$, después de la sublevación de Zacatecas, al parecer, cambió de opinión y dejó que el Congreso realizara el cambio sin comprometer su persona. Es a partir de este momento cuando los santanistas en el Congreso empezaron a votar por el centralismo. Independientemente de este apoyo, es incuestionable que los centralistas no hubieran podido hacer el cambio sin la anuencia de Santa Anna. Esto lo corroboran las diferentes juntas que se celebraron en Tacubaya en el mes de junio de 1835, para tratar el asunto con el presidente.

Por ello, decía el congresista José Ramón Malo:
El general Santa Anna ha llegado a ser sumamente necesario para dar regularidad a la cosa pública y para contener los avances de la ambición, pues hoy todos los que se creen con derecho al mando giran a su derredor como satélites y no salen de su 6rbita. ${ }^{21}$

Esta afirmación de un miembro del partido del orden hace pensar que, sin duda, este partido contaba con la colaboración y presencia del general Santa Anna en el proyecto centralista, sin pensar que una rebelión en la lejana Texas vendría a cancelar esta posibilidad.

Ya desde antes de la campaña militar, los miembros del partido del orden y los santanistas se habían dividido sobre la forma en que el caudillo debería participar en el nuevo orden de cosas al discutir el proyecto de la segunda ley constitucional sobre el establecimiento de un poder conservador. De acuerdo con don Carlos María de Bustamante, se puede decir que se oponían al proyecto los clérigos y militares que querían un rey, el gobierno a través del ministro José María Tornel y algunos congresistas de clara filiación santanista como Antonio Pacheco Leal quien, a pesar de haber suscrito el dictamen como miembro de la comisión, hizo proselitismo entre los representantes para votar en contra del proyecto. 22 En la sesión del día 16 de diciembre de 1835 se votó en lo general y se aprobó sólo por la diferencia de un voto. ${ }^{23}$

21 Malo, Diario, 1948, vol. 1, p. 49.

22 "Diario de Bustamante", citado en Noriega, Pensamiento, 1972 , vol. I, pp. 204 y ss.

23 Congreso, "Sesión del día 16 de diciembre de 1835", Diario del Gobierno de la República Mexicana, 30 de diciembre de 1835 . 
La formación de este cuarto poder era parte esencial del proyecto de los hombres más influyentes del partido del orden. Parece obvia la intención de contar con un poder neutro, como en las monarquías constitucionales, que permitiría la estabilidad del régimen, aunque existieran fuertes divisiones partidarias. Por otra parte, está claro que los hombres de bien pretendían controlar, a través de este mecanismo constitucional, a los caudillos militares que ejercieran el poder ejecutivo y a los excesos de los radicales en el legislativo. La votación muestra que, por diversos motivos, federalistas moderados, algunos centralistas y santanistas se separaban del proyecto de la "elite" del partido del orden.

Durante el año de 1836 y principios de 1837 , y como consecuencia de la guerra de Texas, los santanistas y los del partido del orden se irían separando hasta un rompimiento total. Mientras las noticias eran favorables a las armas mexicanas, el Congreso marchaba unido; se proyectaba crear una legión de honor para premiar los méritos de los militares, se promulgaba una ley de indulto para los sublevados y se facultaba al gobierno en diversos sentidos para mantener la guerra en aquella región. ${ }^{24}$

El gobierno dio cuenta al Congreso de los convenios celebrados por Santa Anna el 23 de junio en sesión secreta.

2414 de abril de 1836, "l.ey", "Indulto a los prisioneros hechos en la guerra de Texas. Ley decreto de la legión militar mexicana de honor", 27 de abril de 1836, Dublán y Lozano, Colección, 1876-1904, vol. In, pp. 142 y 150.

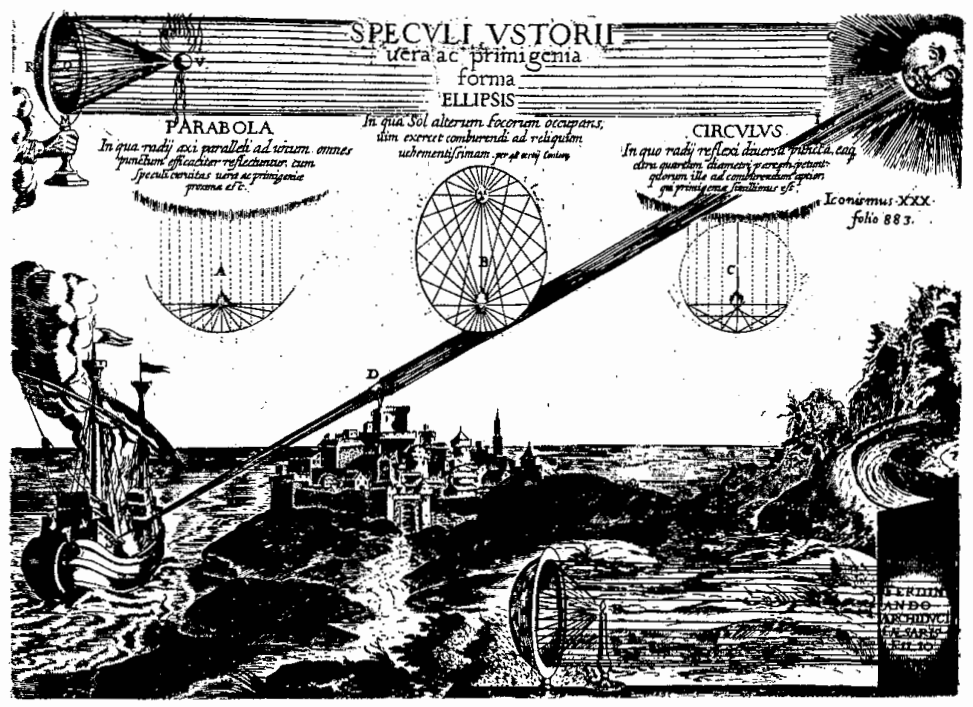


El señor Bustamente pidió la palabra para manifestar la extrañeza que le había causado el que, al darse cuenta con estos documentos, hubiese manifestado el secretario de la Guerra que el general Santa Anna en nada había manchado su nombre, siendo así que el contenido de los convenios que se habían leído al Congreso era de lo más oprobioso para la nación. El señor Tornel se salió por la tangente y señaló la triste situación en que se encontraba, pues tenía que luchar con Ia amistad que lo ligaba con el señor Santa Anna y los deberes que tenía por razón del puesto que ocupaba. El señor Bustamante terminó presentando la siguiente proposición:

Para cuando el gobierno remịta los documentos que se le han pedido se contestará por la Secretaría el sumo desagrado e indignación con que el congreso general había [visto] el contenido de ellas. ${ }^{25}$

El prestigio de Santa Anna iba en descenso a lo largo del año de 1836; la publicación de los tratados con los texanos había actuado en su contra y sólo sus amigos personales se atrevían a dar una interpretación favorable de ellos que a todas luces era insostenible. Al finalizar el año se sabía que Santa Anna había sido liberado y que pronto regresaría a México. Las Siete Leyes estaban por concluirse y sancionarse. Para los miembros del partido del orden se planteaba un problema muy importante: ¿Seguía siendo presi-

25 Congreso, "Sesión secreta ordinaria del 23 de junio de 1836", All, Actas de las sesiones secretas. dente Santa Anna? ¿Había que contar con él para que el proyecto centralista fuera viable a pesar de su desprestigio?

En febrero de 1837 se entablaría una lucha a muerte entre los del partido del orden y los santanistas. El día primero de ese mes Bustamante pidió al gobierno que informara por escrito lo que supiera sobre la libertad de Santa Anna y el objeto de su viaje a Estados Unidos. ${ }^{26}$

Dos días después Bustamante insistió en la presentación de documentos por parte del gobierno, se presentó en la cámara y leyó varias comunicaciones oficiales y artículos de periódicos de Nueva Orleáns. Después de esta lectura presentó a la cámara la siguiente proposición que fue admitida:

1a. El general don Antonio López de Santa Anna luego que regrese de los Estados Unidos del Norte a la República Mexicana instruirá al Congreso con justificación de los motivos de su viaje a Washington, resultados de él y compromisos que pueda haber contraído desde la acción de San Jacinto y, entre tanto, $y$ hasta que el Congreso haga la conveniente declaración sobre todo, no podrá ejercer mando alguno civil ni militar. 2a. Todo el que directa o indirectamente promoviese la desmembración del territorio mexicano (aunque sea en una mínima parte), se declarará traidor a la patria, y castigado con las penas que señalan a este crimen. ${ }^{27}$

26 Congreso, "Sesión secreta extraordinaria del 1 de febrero de 1837", All, Actas de las sesiones secretas.

27 Congreso, "Sesión secreta extraordinara del 3 de febrero de 1837", NIL, Actas de las sesiones secretas. 
La proposición era fuerte, ya que no sólo se suspendían los derechos de Santa Anna, sino que con el artículo segundo, se estaba sugiriendo, veladamente, que el caudillo había incurrido en el delito de traición.

Ia comisión de Texas presentó dictamen sobre las proposiciones de Bustamante el día 10; en él se aseguraba que los colonos habían abusado de Santa Anna al hacerle firmar los convenios; que respecto a si las promesas de Santa Anna fueron falsas o verda. deras, de cualquier modo había de impedir su cumplimiento; que el prisionero estaba inhabilitado para cumplir sus promesas y que necesitaba la rehabilitación del Congreso, sin la cual no podía ejercer cargo alguno; que la medida era justa, conveniente y necesaria para evitar males a la nación. ${ }^{28}$

El día 16 la votación resultó empatada; en ésta se muestra que las fuerzas se habían agrupado de la siguiente manera: la mayoría de los del partido del orden, tanto exaltados como moderados, a favor del dictamen, mientras que los federalistas moderados y los santanistas, en contra. El día 17 se aprobó en lo general por 37 contra 29 votos, después de que los hombres de bien hicieron esfuerzos extraordinarios para reclutar a la gente que no asistía a las sesiones y así alcanzar el número que exigía el reglamento. Posteriormente se aprobaron los artículos $1^{\circ}$ y $2^{\circ} \mathrm{del}$ proyecto, pero se rechazó el

28 "Dictamen de la cómisión encargada de los negocios de Texas sobre las proposiciones del sef́or Carlos María de Bustamante, presentada al Congreso en la sesión del día 10 de febrero del corriente ańo", El Cosmopolita, 15 de febrero de 1837 . $3^{\circ}$ por 34 votos a 30 . En este último artículo es donde se disponía la necesidad de la rehabilitación. 29

Bustamante presentó el día 20, para sustituir el artículo rechazado, uno nuevo: "Se declara que el general don Antonio López de Santa Anna dejó de ser presidente desde la publicación de las nuevas leyes constitucionales." Sin ambages se pretendía que Santa Anna desapareciera del proyecto centralista. El día 22 el Congreso lo puso a votación permanente para concluir con el asunto y, después de dilaciones, subterfugios y toda clase de estrategias por parte de los dos partidos en pugna, se logró la aprobación por $\mathbf{4 0}$ votos contra 24.

Concluida la sesión permanente, se presentaron el oficial mayor encargado de la Secretaría del Exterior y el ministro de Guerra para dar cuenta al Congreso del regreso a la república del general Santa Anna, pidiendo el primero, de parte del gobierno, que se suspendiese toda providencia respecto a dicho general. El presidente del Congreso contestó que, por estar ya dada la ley, y acordado que se remitiera al gobierno en la misma

29 Ia oposición pudo vencer gracias a que algunos hombres del partido del orden cambiaron su voto por miedo a las represalias: Jerónimo Villamil se salio del salón de sesiones y votaron en contra Ignacio Anzorena, Basilio Arrillaga, José Nicolás Bernal, José María Bravo, Atenógenes Castillero, Manuel de Cortázar, Francisco Monter, Manuel Moreno Cora, Jose María Santelices y Terso Vejo. Entre los que más llamó la atención su cambio de opinión fue el padre Basilio Arrillaga, uno de los defensores más vehementes del proyecto de Carlos María de Bustamante. Congreso, "Sesiones secretas de los días 16 y 17 de febrero de 1837", All, Actas de las sesiones secretas. 
sesión, no podía ya tomarse en consideración. ${ }^{30}$

El gobierno no sancionó la ley y mucho tiempo después la regresó al Congreso con observaciones; de hecho no había sido necesaria en la parte fundamental. Santa Anna se refugió en su hacienda de Manga de Clavo, escribió un manifiesto sobre la campaña de Texas y con "humildad" prestó juramento a la nueva constitución. ${ }^{31}$

Los dos partidos en pugna habían logrado en cierta forma sus objetivos: los hombres de bien podían escoger un nuevo candidato a la presidencia de acuerdo con sus requerimientos y los santanistas podían esperar tiempos mejores sin ver comprometidos el honor y los derechos de su líder. Como resultado obvio de este enfrentamiento, los santanistas se distanciarian definitivamente del partido del orden y de su proyecto centralista.

${ }^{30}$ Congreso, "Sesiones secretas extraordinarias del 20 y 22 de febrero de $1837^{\prime \prime}$, Ail, Actas de las sesiones secretas.

${ }^{31}$ Antonio López de Santa Anna al secretario de Guerra y Marina, Manifiesto que de sus operaciones en la campaña de Texas y en su cautiverio dirige a sus conciudadanos, s.e., Manga de Clavo, 10 de mayo de 1837, BN, Colección Lafragua.
La guerra de Texas había hecho imposible un matrimonio entre ambos elementos. El partido del orden tendría que basarse a partir de este momento en sus propias fuerzas y en el prestigio y conexiones de su nuevo líder: el general Anastasio Bustamante.

\section{BIBLIOGRAFÍA}

-Dublán, Manuel y José María Lozano, Legislación mexicana. Colección completa de las disposiciones legislativas expedidas desde la independencia de la repúbli$c a, 34$ vols., edición oficial, México, 18761904.

-Malo, José Ramón, Diario de sucesos notables, Editorial Patria, México, 1948.

-Mateos, Juan Antonio, Historia parlamentaria de los Congresos mexicanos, J.V. Villada, México, 1877.

-Noriega, Alfonso, El pensamiento conservadory el conservadurismo mexicano, Universidad Nacional Autónoma de México, México, 1972.

-Proyectos de ley presentados al Con greso general en las sesiones del $24 y$ 25 de septiembre de 1835 por la comisión respectiva sobre reorganización de la república, J. M. Femández de Lara, México, 1835.

-Sordo Cedeño, Reynaldo, "El Congreso en la primera república centralista", tesis de doctorado, El Colegio de México, México, 1989. 

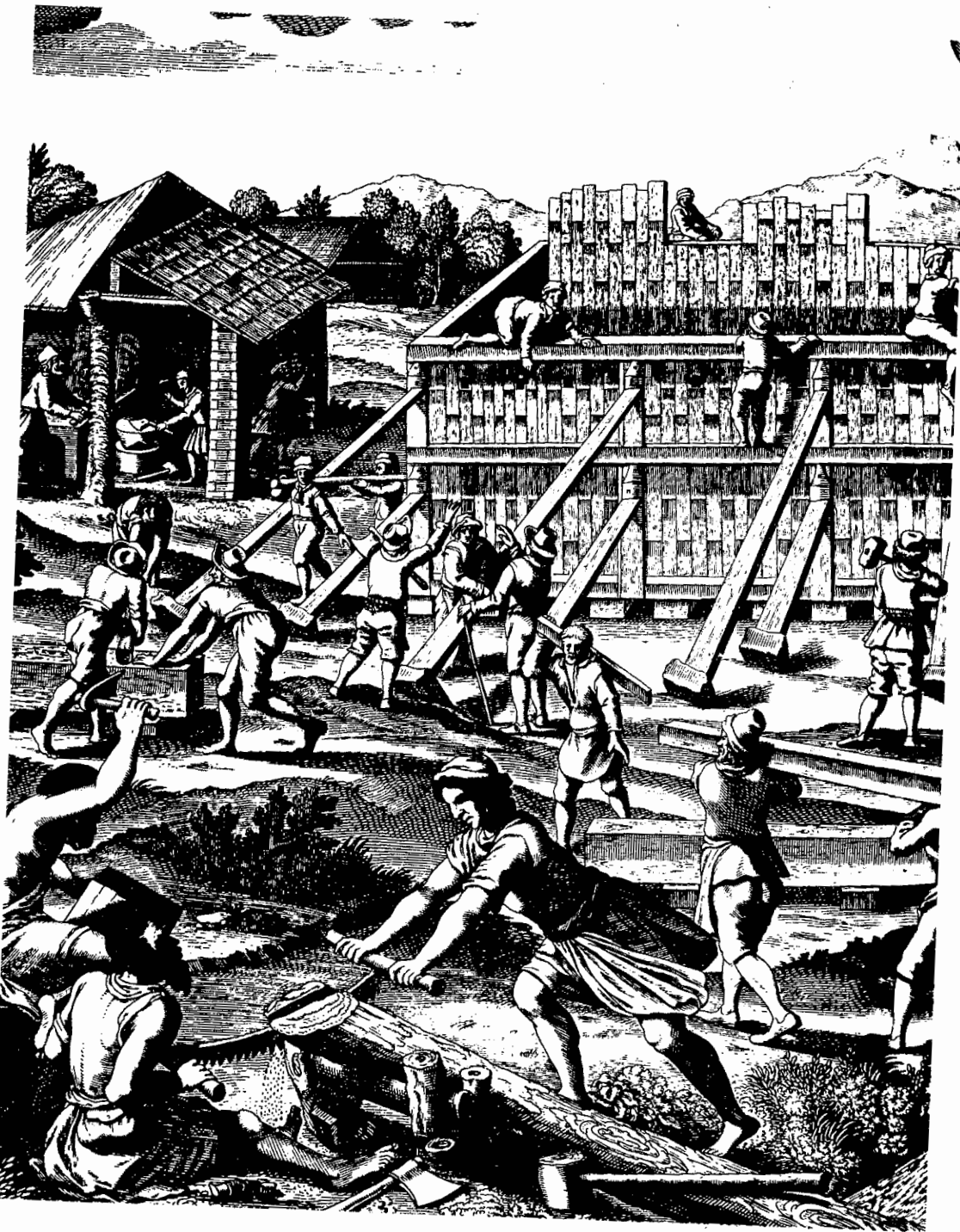